\title{
Confusões de escala e espelhamentos em Instantâneo da desmedida, de Vilma Arêas
}

\author{
Confusion of Scale and Mirroring in Instantâneo da desmedida, by Vilma Arêas \\ Confusiones de escala y reflejos en Instantâneo da desmedida, de Vilma Arêas
}

Mariângela Alonso*

\section{Resumo}

Este artigo busca analisar o espelhamento presente em Instantâneo da desmedida, penúltimo texto de Um beijo por mês (2018), de Vilma Arêas. Ao criar uma personagem que, em visita a uma galeria de arte, depara-se com fotografias de diferentes escalas, a autora possibilita um jogo abismal capaz de gerar reflexões em torno da própria arte literária, uma vez que o arranjo dos objetos articula ocorrências que perturbam a espectadora, confundindo-a quanto à real escala das cenas e espaços, tais como os "instantâneos" do volume de Arêas. Com base nessas considerações, salientamos a mise en abyme como uma das bases de produção da escrita de Vilma Arêas. Para tanto, lança-se aqui a proposta de uma análise possível ao texto mencionado a partir das formulações de Lucien Dallenbach (1979; 1977; 1972), entre outros teóricos. Ademais, as reflexões de André Malraux (2006; 1996) acerca do museu imaginário auxiliarão na discussão.

Palavras-chave: mise en abyme, museu imaginário, Vilma Arêas, Um beijo por mês.

Abstract

This article aims to analyze the mirroring present in "Instantâneo da desmedida," the penultimate text in Um beijo por mês (2018), by Vilma Arêas. By locating her character in an art gallery with photographs of diferente scales, the author enables an endless game capable of generating reflections around literary art itself, since the arrangement of objects articulates occurrences that disturb the spectator, confusing her as to the real scale of scenes and spaces, like the "snapshots" of Arêas's volume. Based on these considerations, we highlight mise en abyme as one of the foundations of Vilma Arêas' writing. To this end, the proposal for a possible analysis of the mentioned text is launched here from the formulations of Lucien Dallenbach (1979; 1977; 1972), among other theorists. Furthermore, André Malraux's (2006; 1996) reflections on the imaginary museum will help in the discussion.

Keywords: mise en abyme, imaginary museum, Vilma Arêas, Um beijo por mês.

\section{Resumen}

Este artículo busca analizar el reflejo presente en Instantâneo da desmedida, penúltimo texto de Um beijo por mês (2018), de Vilma Arêas. Al crear un personaje que, en una visita a una galería de arte, se encuentra con fotografías de diferentes escalas, el autor permite un juego abismal capaz de generar reflexiones en torno al arte literario, ya que la disposición de los objetos articula acontecimientos que perturban a la espectadora, confundiéndola en cuanto a la escala real de escenas y espacios, como las "instantáneas" del volumen de Arêas. En base a estas consideraciones, destacamos mise en abyme como uno de los fundamentos de la escritura de Vilma Arêas. Con este fin, la propuesta para un posible análisis del texto mencionado se lanza aquí a partir de las formulaciones de Lucien Dallenbach (1979; 1977; 1972), entre otros teóricos. Además, las reflexiones de André Malraux $(2006$; 1996) sobre el museo imaginario ayudarán en la discusión.

Palabras-clave: mise en abyme, museo imaginario, Vilma Arêas, Um beijo por mês.

* Universidade de São Paulo (USP), São Paulo, SP, Brasil. (Dorcid.org/0000-0003-3521-0051. E-mail: profamary1920@ gmail.com 


\title{
Museus imaginários: esferas criadoras e espaços fronteiriços
}

\author{
Da minha aldeia vejo quanto da terra se pode ver do Universo... \\ Por isso a minha aldeia é tão grande como outra terra qualquer, \\ Porque eu sou do tamanho do que vejo \\ E não do tamanho da minha altura..
}

Fernando Pessoa, Alberto Caeiro

O inventário contemporâneo de imagens tende a exceder toda e qualquer aptidão no que tange à atenção do espectador. O bombardeio simultâneo de acontecimentos invade as telas de televisão e mídias sociais todo o tempo. Aventa-se um cenário disruptivo, ligado sobremaneira à percepção de um presente contínuo, agudamente direcionado ao futuro. Tal proeminência de imagens apresenta muitas vezes a negligência ao detalhe, marcado pela mera participação do sujeito na cadeia visual. O resultado é uma sequência de distrações vazias e incompletas deste mesmo espectador.

A constante aproximação desse universo de imagens no cotidiano possui um alcance intenso e acaba por também modificar a atitude do cidadão em relação à arte, induzindo-o a certa indiferença ou anestesia. Criada em uma espécie de interstício temporal e espacial, a arte configura-se pela imprevisibilidade, tornando-se apreensível àqueles que estão dispostos a experiências estéticas em contínua construção. Nesse contexto, passa-se à reflexão acerca do fazer artístico, observando seus produtos e processos imersos na sociedade de consumo, bem como as possíveis interações na sociedade.

A arte é, acima de tudo, um modo de transformação do mundo na medida em que incita o indivíduo a tomar consciência dos embates a sua volta. Assim, podemos compreender o espectador a partir da configuração de elementos estratégicos para o entendimento das ligações nesse espaço, considerando ao mesmo tempo seu ponto de vista e sua imprevisibilidade em relação aos objetos artísticos. Trata-se, portanto, de considerar as possibilidades que o espectador possui ao criar relações frente às obras artísticas em exposições e museus, por exemplo.

Acresce que, como um de seus intentos, a arte contemporânea busca a inovação, não se revelando inteiramente a seus espectadores. Ao guardar sempre elementos escondidos, dificulta a tarefa de percepção e organização empreendidas pelo espectador. Prova disso são os inúmeros trabalhos realizados após os anos 1960, cuja essência voltava-se a reflexões em torno dos próprios procedimentos artísticos ou ainda acerca de suas relações com a vida cotidiana. Conforme já afirmara Marcel Duchamp (1986), nessa dinâmica com o trivial, o espectador é parte ativa da criação artística ao experimentar o processo de transmutação: "o público estabelece o contato entre a obra de arte e o mundo exterior, decifrando e interpretando suas qualidades intrínsecas e, desta forma, acrescenta sua contribuição ao ato criador" (Duchamp, 1986, p. 74). Desse modo, o artista não tem o domínio absoluto sobre a formulação elaborada pelo espectador que se vale de suas criações, configurando uma dosagem extrema de indeterminação. Qualifica-se um jogo crítico e participativo, no qual a exposição configura-se como um código de representação e comunicação, em que não há propriamente o lugar do destinatário, mas, sim, um espaço em que todos os participantes são agentes de uma mesma esfera criadora de novas situações. É exatamente nesse hiato ou silêncio repleto de significados que ocorre o diálogo artístico. Vale ressaltar que os pontos cegos podem ser ou não completados, mas antes de tudo ressignificam a essência artística ao exibir suas qualidades e incompletudes. Sua função é situar a arte numa espécie de espaço fronteiriço, cuja interação demanda a comunicação do espectador com a obra e vice-versa.

Decerto, as exposições ocupam o imaginário e propõem muito mais ao levantar questões do que fechar interpretações, incitando um olhar mais complexo do visitante ao fitar as obras de determinado artista. A apreciação torna-se reflexão e concomitantemente criação do espectador. No tocante a essa complexa relação, a ação do visitante sintoniza-se com a reflexão crítica do francês André Malraux em torno dos chamados museu real e museu imaginário. No ensaio Le musée imaginaire, publicado em 1947, o estudioso discute a função dos museus, salientando que estes 
trouxeram um novo tipo de relação entre o visitante e a obra de arte. Na profícua interação entre museu, cultura e sociedade, sobressai a seguinte proposição: "o museu foi uma afirmação, o museu imaginário é uma interrogação" (Malraux, 2006, p. 176, tradução nossa). Notoriamente valorizado, o museu imaginário é espaço de produção de sentidos e confrontação de olhares, de modo a oferecer um diálogo entre o sujeito e sua imaginação. Nessa perspectiva, constitui-se como um fenômeno mental que provém de experiências visuais e cumulativas. Trata-se de um espaço desprovido de existência física ao ganhar forma na mente do espectador materializando-se por meio de proposições visíveis, tais como a fotografia. Logo, a noção de museu liga-se aos pontos de vista de confronto e beleza como mediadores essenciais entre o sujeito e sua herança histórica e cultural: " $\mathrm{O}$ museu impõe o questionamento de cada expressão do mundo que reúne um questionamento do que os une. Ele não conhece nem proteção, nem objeto de veneração, mas imagens de coisas diferentes das próprias coisas" (Malraux, 2006, p. 13, tradução nossa).

Quer protagonizada pelo espectador como fruição, quer depreendida como mistério, a arte passa a oferecer novas experiências, cujas operações centram-se em processos de desmontagem do objeto observado. Assim, tomar conhecimento do processo de criação de certas obras contemporâneas constitui muitas vezes condição essencial para a interação de forma a incitar a recepção estética. Tais questões não deixam de se fazer sentir em Instantâneo da desmedida, texto presente no volume Um beijo por mês, de Vilma Arêas. Assim, na sequência desta exposição, procuraremos tratar das reflexões acima apontadas, articulando-as com o jogo de especularidade da mise en abyme.

\section{Confusões de escala e espelhamento:}

Publicada em 2018, sete anos após Vento sul, a coletânea Um beijo por mês, de Vilma Arêas, apresenta, sem sombra de dúvidas, um dos pontos altos da obra da autora e estrutura-se, em larga medida, sobre "recortes" que fogem a qualquer definição: "Inacabadamente acabados, esses textos fazem o leitor reconsiderar a si mesmo e às palavras, olhos nos olhos" (Jaffe, 2018, s.p.).

O livro se compõe à maneira de um mosaico, cujas mesclas compreendem as faces sociais, culturais e, sobretudo, artísticas da escrita literária, de modo a propiciar um intrigante e disforme painel. Tais recortes abordam situações inusitadas do cotidiano, bem como descrições imagéticas presentes em exposições, catálogos ou matérias jornalísticas. Tudo construído na esfera de definição dos dois sentidos do termo "recorte":

1. "ato em que o toureiro se encontra no mesmo ponto com o touro, no momento em que este baixa a cabeça para marrar" (Lello Universal). Estão, pois, no "terreno da verdade", ou seja, na arena, o lugar do combate.

2. Recorte, recortar. Derivados de recorder, "tener recuerdo de lago" (Joan Corominas, Breve Diccionario de la Lengua Castellana) (Arêas, 2018, p. 7).

$\mathrm{O}$ aspecto mais intrigante da reunião de textos de Um beijo por mês talvez esteja no exercício singular e curioso em torno da trivialidade capturada pelas formas ariscas e diluídas de seus "instantâneos". A propósito, figuram nesta coletânea textos que alternam o foco entre o público e o privado, favorecendo certas irregularidades próprias da obra de Arêas já presentes em volumes anteriores, como Partidas (1976), A terceira perna (1992) e Vento sul (2011). Conforme observa Rita Chaves, os limites entre os mundos subjetivo e objetivo são borrados e "a experiência da perda, se vem de fora, se processa também no interior, eximindo-se num movimento que vai desaguar numa linguagem carregada de acertos e incertezas" (Chaves, 2018, p. 96). Nesse sentido, surpreende, pois, a intensa mobilidade e sensibilidade do narrador quanto à apresentação desordenada de tais "instantâneos": Instantâneo (4) seguido pelos (2) e (3) e finalmente pelo (1). Revertidos em escrita fluente e despretensiosa, estes textos revelam-se como recortes que trazem impressões acerca de fotografias artísticas, como a exposição Gente Bahia, de Luciano Andrade, na galeria fotóptica de Pinheiros, São Paulo; a capa da revista Carta Capital de agosto de 2014, que suscita o debate e a fragilidade social ao trazer o tema da maioridade penal; uma notícia de jornal intitulada Caçada, a qual capta sinais de violência em 
uma comunidade; e, finalmente, a descrição de um pedaço de papel colado em uma geladeira que se revelará como uma das caricaturas de Henfil. Esta habilidade em amontoar recortes e linhas fugidias apenas sinaliza um dentre os muitos casos ou impressões relatadas na coletânea. Na realidade, Arêas traz à baila ocorrências que, ora descritas, realçam estranhas apreensões em torno da fruição estética. Daí ser inevitável enunciarmos o diálogo com a definição de Malraux a respeito do museu imaginário como interrogação. Interrogar-se a respeito destes textos é o que resta ao leitor de Um beijo por mês. A mesma interrogação aguda perpetua-se na escrita da autora, na medida em que interroga a arte fotográfica e, por extensão, a arte literária. Nessa coletânea, tanto a fotografia quanto o desenho "emergem e partilham com a palavra o direito e o dever da construção de sentido que essa literatura exige" (Chaves, 2018, p. 98).

Com efeito, tal observação parece ajustar-se ao singular perfil de Instantâneo da desmedida, penúltimo texto da coletânea. Nele, a personagem visita a série Desmedida, da artista gaúcha Rochelle Costi (Caxias do Sul, 1961), exposta em 2009 na galeria Luciana Brito, em São Paulo. A exemplo da Alice, de Lewis Carroll, a mulher espanta-se ao mirar a confusa exposição, inspirada em uma casa de madeira em miniatura: "Ela ultrapassou o umbral, observando que pelo lado de dentro a porta era igual a de uma casa velha, de madeira gasta, esfolada" (Arêas, 2018, p. 67).

Na mostra de Costi, o arranjo dos objetos articula ocorrências que perturbam o espectador, confundindo-o quanto à real escala das cenas e espaços da casa. A frágil linha que separa os limites de mundo ficcional e mundo real torna-se ainda mais débil quando as intervenções de madeira invadem o cenário, acabando por tornar-se um espaço contíguo às fotografias apresentadas. Com certeza, o enlevo da experiência reside no ofegante jogo de escala, com a duplicidade de situações, ora nítida, ora velada, com soluções ambíguas ou contraditórias nos cômodos da casa minúscula. Conforme explicara a própria artista em declaração ao periódico mineiro O tempo:

Um dado recorrente no meu trabalho é o registro de interiores. O "Desmedida" é uma mudança a partir disso. Peguei uma casa pequena, uma maquete, com aberturas externas, o que me permitiu abordá-la com a câmera da mesma forma que abordo casas reais. Coloquei ali dentro elementos que provocam uma dúvida com relação à escala. A ideia é essa, provocar um incômodo e a reflexão sobre que tamanho a gente tem no mundo (Barbosa, 2010, s.p.).

Depreende-se do depoimento acima três fatores que definem a arte fotográfica de Rochelle Costi, a saber: o envolvimento do trabalho do artista, a interferência dos espaços expositivos e a relação com o espectador. De modo geral, essas três esferas estão presentes nos trabalhos efetuados em série, muitos deles criados a partir de sua atuação no fotojornalismo, entre eles na Revista da Folha. Estrábica na infância, Costi desde cedo teve contato com inúmeros aparelhos óticos em virtude dos tratamentos a que foi submetida. Este fato acabou por despertar a atenção da artista para o sentido visual, que repercutiu e ganhou força em sua trajetória fotográfica.

Vale mencionar que o interesse de Costi por casas e espaços íntimos remonta à década de 1980, mais especificamente a 1982, a partir de uma imagem de um quarto de fazenda no interior de Minas Gerais, conforme conta a própria fotógrafa em 2005, em entrevista ao site Uol. Posteriormente, em 1998, expôs na XXIV Bienal de São Paulo a série "Quartos-São Paulo", trazendo fotografias de quartos de distintas classes sociais. Ao realizar esta série, a artista adentra a intimidade dos lares, reforçando o aspecto etnográfico das imagens, as quais trazem narrativas temporais e espaciais, além de se apresentarem como construções sociais e culturais da cidade de São Paulo. Para além do simples mapeamento e apresentação, a exposição postula o trabalho da artista em materializar no objeto artístico questões íntimas de cada indivíduo numa sociedade extremamente diversa: "Essa busca da intimidade é a forma de mostrar a minha intimidade através dos outros e vice-versa" (Costi, 2005, s.p.).

$\mathrm{Na}$ década de 2000, esse interesse continuou em trabalhos como "Casa cega", "Casa de praia", "Mudanças", "A casa como monumento", "Verdadeiras ilusões". Entre as séries fotográficas citadas, cabe comentarmos uma imagem de "Casa cega". Trata-se do registro da fachada de uma casa pichada. De modo emblemático, surge no lado direito da foto o traço de um retângulo com um triângulo na parte superior, o que imediatamente remete a uma 
miniatura da mesma casa, à maneira de desenhos infantis. A ausência de janelas sugere ao espectador a sensação de enclausuramento e justifica o título "Casa cega".

No ano de 2018, a fotógrafa retoma "as casas", apresentando na Galeria Luciana Brito - a mesma do conto de Arêas - uma exposição em que lançava mão de diversos suportes para a impressão de fotografias: tecidos, pinturas, imagens em diferentes tamanhos, vídeos etc. $\mathrm{Na}$ ocasião, foram apresentadas instalações com casas em tamanhos diferentes, além de um vídeo intitulado "Há casas", com referências de fotos e cenas da procissão Círio de Nazaré, em Belém do Pará, com fiéis carregando miniaturas de casas de madeira ao lado de imagens de casas reais de moradores da cidade de Jordão, no Acre. Tais obras apontam para algumas constantes da fotografia de Costi, como a recriação do cotidiano, que passa a ser repensado e ressignificado nos espaços expositivos de arte: "A fotografia, na obra da artista, revela-se um mapeamento do doméstico como forma de atingir o universal" (Cypriano, 2005, s.p.).

Dessa forma, na exposição Desmedida, o espaço é abordado enquanto aparência e correlação com seu contexto. Sobressai o interesse pelo aspecto singular do elemento decorativo, visível no aumento dos formatos e volumes desenvolvidos em série. Nessa dinâmica, resta a abordagem com o ordinário e residual, na medida em que surgem reduplicações fraturadas e caleidoscópicas da lente da artista. Assim, a desorientação das fotografias propõe diferentes perspectivas de olhar para os objetos, ao mesmo tempo que propicia condições e questionamentos do visitante em torno do cenário observado.

Sem dúvida, salta à vista uma nova expografia, que impede a apresentação do trabalho como algo distanciado do espectador, visando outro conceito de recepção a partir da participação. Sublinha-se um novo entendimento, pautado no jogo e na imersão do público na produção artística. No mais, a exposição de Costi apresenta um conjunto de irregularidades constituídas por uma linguagem específica, a fotografia, modalidade artística que confere estranhamento e desconfiança ao visitante. Na criação desse cenário, a artista convida o espectador a engolfar-se nas desproporções da casa, que, tal como a função poética, extrapola os sentidos, ao apresentar no espaço expositivo o que é invisível ao olhar e se apresenta como uma espécie de dispositivo que liga diferentes escalas, implicando as visões do artista e do público, configurando-se como exercício disparador de fruição. Assim, quase como uma experiência iniciática num mundo despido de convenções e escalas, a mostra sugere à personagem de Arêas que a imagem enquanto objeto perde seu valor, na medida em que o modo de apresentação dessa mesma imagem é o que em definitivo toma lugar e importância:

Num dos quartos um monte de carvão, ou pedras escuras se acumulava até a metade das paredes; em outro, duas imensas caçarolas coloridas; de repente uma pedra clara parecia atingir o teto; o outro era quase todo ocupado por bules de louça arrumados em forma de cacho de uvas, pendentes do alto, talvez de um gancho; os demais guardavam placas altíssimas, latas imensas, instrumentos colossais de ferro encostados nas paredes, enquanto no chão era possível ver estrelas quebradas também de ferro (Arêas, 2018, p. 68).

Exploradora, a personagem procura descobrir as múltiplas leituras potenciais contidas na exposição: "A inquietação do início começou a se transformar num certo mal-estar misturado à curiosidade. O que significaria uma casa vazia cheia de objetos imensos?" (Arêas, 2018, p. 68). Ao mesmo tempo referenciais e simbólicas, as fotografias de Costi forçam a espectadora a uma dupla leitura, uma vez que as escalas e os ângulos capturados pela artista possuem pontos de vista diferentes acerca de um mesmo objeto. Isso mostra à protagonista como a representação do real pode ser efetuada de muitos modos e, por conseguinte, a relatividade da própria representação das coisas, desdobrando-se de forma duradoura em fruição.

As imagens decalcam-se no imaginário da personagem como projeções e representações em que o ato de ver e pensar estão imbricados. Dessa maneira, a exposição corrobora percepções mistas, na medida em que a fruição propicia questionamentos intensos acerca das fotos e espaços, cujas presenças inopinadas acabam por irritar a espectadora: "Francamente! - pensou a visitante. Levou o catálogo sem abrir" (Arêas, 2018, p. 68). Logo, o mecanismo fruidor é acionado pela qualidade da obra de Costi, que, ao desrealizar a realidade, apresenta-a em uma nova dimensão, convidando a visitante a adentrar a curiosa casa por meio de seu imaginário. Parece-nos 
inevitável, nesse ponto, mencionarmos a famosa definição de Roland Barthes (1987) acerca das diferenças entre leitura de fruição e leitura de prazer. Enquanto esta última admite a extenuação rápida das sensações, a leitura de fruição, por sua vez, conserva-se em seu estado inquiridor, permitindo ao leitor maiores questionamentos: "[...] faz vacilar as bases históricas, culturais, psicológicas, do leitor, a consistência de seus gostos, de seus valores e de suas lembranças, faz entrar em crise sua relação com a linguagem" (Barthes, 1987, p. 24). Tal como a palavra poética vista em seus múltiplos significados, a exposição Desmedida prima pela transgressão dos discursos expográficos oficiais, na medida em que estabelece uma relação em que atribui um espaço privilegiado aos espectadores. Sob essa ótica, ganha outros significados, renunciando à recepção meramente passiva. Este raciocínio pode ser completado com as proposições de André Malraux em torno do museu como um amálgama de encontro e confronto:

Manter a herança humana é uma de nossas maiores tarefas, e é claro que esse projeto não é suficiente. Mas é tanto na direção de uma disseminação do conhecimento quanto de um confronto. É, portanto, o significado de nossa atividade. Pois o que o ocidente chama de cultura é, acima de tudo, por quase quinhentos anos, a possibilidade de confronto. (Malraux, 1996, p. 140, tradução nossa).

Diante da dificuldade de definir a concepção estética a partir das obras de Costi, a visitante conta com o auxílio de Francisco, personagem que esclarece os limites de tal experiência, perscrutando o catálogo da exposição: "O que você viu com certeza foram fotos muito ampliadas de uma casa minúscula, pendurada nas paredes de uma casa de tamanho normal. Era uma exposição, não era?" (Arêas, 2018, p. 69).

Imersa num processo extremamente complexo cercado de ambiguidade e espelhamento, a personagem torna-se confusa, acabando até mesmo por esquecer a direção de sua narração, tornando-se perdida: "Tinha se transformado numa espécie de Alice, aludida pela artista numa entrevista. Ao atravessar a porta, tropeçou e caiu num túnel, acabando por desabar na casa de bonecas fotografada por Costi" (Arêas, 2018, p. 69-70).

Todo esse sistema confuso e espelhado tende a funcionar como uma alegoria da posição do leitor que, tal como a mulher, encontra-se perdido, procurando um caminho possível em meio aos labirintos vertiginosos das escalas e, por extensão, da própria literatura. A narrativa se sujeita ao trânsito, ao nomadismo de instâncias, propondo novas configurações estéticas à obra literária. Tal dinâmica afeta diretamente o leitor, sobretudo no que tange à capacidade interpretativa e criativa deste na atribuição de sentidos.

O jogo de espelhamentos entre a exposição e a personagem abrange, portanto, o exercício literário da própria autora, uma vez que ganha forma a discussão acerca do que porventura poderia ser configurado como a essência mesma do texto literário:

A mudança de escala é um procedimento insistente da artista. Não se trata de arbitrariedade, ou de algo igualmente frívolo, mas pode ser compreendido como uma espécie de conceito, caracterizado por sua extensão, pois instaura associações, passagens de uma coisa a outra, e também compreensão, em sua capacidade de relacionar elementos íntimos e 'situações reais', objetos soltos e as classes, passado e presente (Arêas, 2018, p. 70).

Desse modo, rastrear as fotografias de Costi significa, antes de tudo, percorrer a tentativa de compreensão de um projeto ficcional, aberto, nômade e espelhado em meio a vários recortes e/ou instantâneos descritivos de imagens aleatórias, que definem e compõem o livro de Arêas. Conforme afirmara Rita Chaves acerca do presente conto no posfácio do volume: "O objeto é o trabalho de Rochelle Costi. Mas não poderia ser este volume que Vilma Arêas nos entrega?" (Chaves, 2018, p. 98). Nesse sentido, a literatura de Arêas ultrapassa a mera questão técnica, revelando-se artificiosamente mais complexa, já que o abismo e as confusões de escala tendem a funcionar como o próprio lugar da ficção e o ponto em que o texto revela simbolicamente seu estatuto de literatura como tal:

Ela via a casa e se via a si mesma, como no capítulo cinco, "Conselhos de uma lagarta", de As aventuras de Alice no país das maravilhas. No livro de Carroll, aumentando e diminuindo de tamanho, Alice de repente passou a ter um pescoço tão comprido como aquele imenso 
tubo branco na casa de bonecas, certamente uma alusão à história. [...] Alice saíra das maravilhas de Carroll para cair nas desmedidas de Costi (Arêas, 2018, p. 70).

Pode-se dizer que Instantâneo da desmedida trata, portanto, de duas narrativas contrapostas, a saber: a visita e perturbação da mulher diante da exposição de Costi e a visita da autora em torno de seu exercício literário. Entretanto, pela própria composição espelhada, as duas histórias tendem a se constituir numa única, e singularmente retornam a si, confundindo-se com o jogo de escalas. Esse recurso original contribui para manter a rede de possibilidades que cerca a narrativa, abrindo-se como uma fronteira lúdica ao leitor, que precisará se adaptar às confusões de escala para vivenciar a fruição e experiência de leitura. A questão que se põe nessa estrutura em abismo concerne ao texto a chamada mise en abyme, procedimento narrativo definido pelo escritor francês André Gide em fins do século XIX: "Gosto que em uma obra de arte se encontre assim transposto, à escala dos personagens, o pano de fundo desta obra. Nada o esclarece melhor nem estabelece mais seguramente todas as proporções do conjunto" (Gide, 1948, p. 41 apud Dallenbach, 1977, p. 15, tradução nossa). Originário da heráldica, o famoso termo configura um escudo trazendo em seu centro uma miniatura de si mesmo, a fim de expressar processos de profundidade e infinito, o que significa propor, na esfera literária, ideias de reflexo ou espelhamento. Ao refletir sobre seus funcionamentos, o texto engolfa-se sobre si mesmo ao jogar com as mediações de enunciado, enunciação e código, segundo as formulações do teórico Lucien Dallenbach em Le récit spéculaire (1977), estudo que fornece a compreensão de aspectos essenciais do assunto. Todavia, é preciso salientar que esta técnica não se relaciona apenas ao nível do sujeito ou dos personagens, mas também ao nível da relação escritor-escrita, caracterizando-se por um alto teor de reflexividade, o qual deve ser captado com o auxílio de ferramentas críticas e sociocríticas da obra literária, conforme observado por Véronique Labeille (2011), outra estudiosa do tema. Nessa perspectiva, mais do que um espelho, há, na mise en abyme, algo como um caleidoscópio ou fractal capaz de propiciar, à luz de diferentes ângulos, pela sua reduplicação, não somente o encaixe narrativo presente, mas também a atualidade contemporânea, social e artística da obra literária. Assim, Labeille propõe a imagem de um "prisma" em substituição à do espelho: "Mais ainda, para permanecer na metáfora ótica, propomos a figura do prisma, espelho quebrado, permitindo intervalos entre a imagem e o seu reflexo" (Labeille, 2011, p. 104, tradução nossa). Logo, na narrativa de Arêas, a participação da mise en abyme é estabelecida não somente pelo simples movimento de encaixe de uma narrativa maior a uma menor, mas, sobretudo, pela cumplicidade de uma ficção a uma realidade, ou ainda, por uma idealidade a uma materialidade, como nos mostra o narrador em tom ensaístico: "Rochelle Costi não usa manipulação digital nem recursos de luz artificial. Afirma que sua principal ferramenta é 'a verdade no fazer perceber'” (Arêas, 2018, p. 70). Nesse sentido, emerge uma realidade evocada pela autora, que designa a ficção, conferindo uma significação conflitante tanto à exposição de Costi quanto à literatura, tal como previa Malraux a respeito do museu imaginário. Responsável por fundar uma consciência no indivíduo acerca dos produtos artísticos, este museu permitia a chamada "intelectualização da arte" (Malraux, 2006, p. 13, tradução nossa). Evocadores da história, tais produtos exerciam papel primordial na relação entre os espectadores e suas heranças histórico-culturais.

Sectária desse raciocínio, a mise en abyme parece então manifestar-se em Instantâneo da desmedida como o meio possível de a autora tornar-se interlocutora de si mesma. Daí ser possível a estrutura de espelho, que, em sua continuidade, sugere um movimento análogo a uma força centrípeta, que pouco a pouco adentra os universos artísticos da fotografia e da literatura. Ademais, o jogo especular acaba por se situar ao lado da arte, já que esta reflete a vida, e a indagação em torno da escritura ocupa lugar privilegiado. Desse modo, ao citar a arte de Rochelle Costi, pontua a personagem: “[...] as séries de associações formam uma 'espécie de malha de culturas, texturas, cores, padrões', que não deixam de traçar uma narrativa desassossegada para quem souber ler" (Arêas, 2018, p. 70).

A mise en abyme aí contida revela o código narrativo, na medida em que denuncia a ilusão referencial da obra de Vilma Arêas. Ao demonstrar e discutir o trabalho de produção da fotógrafa, o instantâneo dobra-se em si mesmo, colocando-se en abyme. Em termos de fruição, pode-se dizer 
que as particularidades levantadas por Instantâneo da desmedida chamam a atenção para o lugar ocupado pela mise en abyme no campo artístico, atentando para uma espécie de chave de leitura dada aos leitores tanto por Rochelle Costi acerca de suas fotografias, quanto por Vilma Arêas e sua literatura. Pela relação de espelhamento, a técnica tende a questionar a vulnerabilidade artística ao obrigar o leitor a reconhecer o aspecto espelhado, poroso e incerto das confusões de escala: "Se você se desequilibra e perde o pé, é que 'esqueceu que lembrava'. Traçar o caminho de volta para ver bem exige a presença da poesia das palavras e das formas" (Arêas, 2018, p. 71).

Na verdade, a personagem serve-se das escalas confusas de Costi como a um palimpsesto, não se limitando somente à apreciação; é parte dela também a revisitação incessante de sua própria escrita. Para além de uma prática diletante, o instantâneo passa a ser espaço metarreflexivo de busca de sentido e fruição, périplo de percepções mistas e insólitas, tal como Alice experimentara no país dos espelhos. Retomando uma frase de Michel Butor, "toda ficção se inscreve pois em nosso espaço como viagem" (Butor, 1974, p. 41), arriscamos dizer que Vilma Arêas instala sua câmera na exposição de Costi encontrando as mesmas dificuldades de enquadramento e composição que encontra a fotógrafa. Como esta, esforça-se para captar e exprimir as profundidades e superposições de sua arte, sinalizando as lacunas entre o espaço da ficção e o da realidade: "Talvez fosse um rosto de criança, embora os supercílios estivessem maquiados, sublinhados a lápis. Estaria apenas desenhada? " (Arêas, 2018, p. 67). Trata-se de um ímpeto que move a visitante, na medida em que movimenta pontos de vista e consequências, o que, não por acaso, também se efetua como condição essencial do texto, no trato com a matéria que se expõe em terceira pessoa, entrecortando-se com a consciência da protagonista. Conhecer-se e desmembrar-se num outro, seja ele um morto, uma foto ou uma escala: "O rosto que parecia morto pode ser redesenhado e tornado vivo, assim como fotografou Rochelle Costi" (Arêas, 2018, p. 71).

A presença do campo fotográfico possibilita um encontro com o que Lucien Dallenbach chama de "suporte temático" da mise en abyme. Para o teórico, a técnica só atinge "o pleno regime" quando abordada ao lado de exemplos relanceados das demais artes, tais como "pintura, peças de teatro, fragmentos de música, romance, conto, novela, tudo se passa como se a reflexão, para levantar voo, devesse pactuar com uma realidade homogênea da que reflete: uma obra de arte" (Dallenbach, 1979, p. 67). Embora Dallenbach não mencione a fotografia, podemos aqui incluí-la, uma vez que é possível encontrar relações estruturais entre esta arte e a literatura, ainda que ambas sejam detentoras de linguagens distintas. Essas relações encontram-se presentes no âmago etimológico do termo "fotografia", oriundo do grego, o qual denota foto=luz/grafia=escrita, significando "escrever com luz". Destarte, tais linguagens se imbricam e se complementam, fortalecendo uma posição criativa, já que o escritor desvela a realidade por meio de palavras fixadas em imagens pelo fotógrafo. Ambos partilham modos de olhar e revelar o mundo, como notara a ensaísta americana Susan Sontag (2004) em clássico ensaio sobre o tema. Para Sontag, a articulação dos registros imagéticos constitui uma arte bem próxima da poesia, uma vez que oferece um olhar novo acerca da realidade: "As fotos, que brincam com a escala do mundo, são também reduzidas, ampliadas, recortadas, retocadas, adaptadas, adulteradas. [...] Fotos, que enfeixam o mundo, parecem solicitar que as enfeixemos também" (Sontag, 2004, p. 8-9).

Com efeito, a fotografia potencializa uma dinâmica que contribui para um melhor entendimento da obra literária de Vilma Arêas. Ao causar incômodo na visitante, as fotos conduzem ao questionamento de elementos constitutivos, suscitando leituras imbricadas no mistério da criação de Arêas e na arte fotográfica. Como postulou Lucien Dallenbach, as análises em torno das mises en abyme restariam mutiladas e incompletas, caso o leitor não se voltasse sobre seus "suportes temáticos" supracitados: "Mas, esta busca dentro e no meio da narrativa, não seria a busca da narrativa em si ao encontro de seu lugar e de seu tópico?" (Dallenbach, 1979, p. 91). Pois esta confluência sugere que cada elemento da composição seja o resultado de fotogramas diversos, isto é, capturas diferentes de tempo e espaço. A discussão traz à tona a escrita de Instantâneo da desmedida como uma fotocomposição que fornece um registro peculiar do texto, no qual a câmera lenta e a ampliação deixam transparecer o labirinto da casa de bonecas em uma variedade de planos específicos: "A morta da capa está morta mesmo. É a metade do rosto de uma boneca, fotografado de baixo para cima num suporte escuro" (Arêas, 2018, p. 68-69). Essa 
fotomontagem insinua um ambiente confuso, já que a composição apresenta aspectos que não se relacionam na realidade física e consciente da visitante: "Não tinha entendido direito. O pior é que não pôde trocar impressões, pois era o último dia da exposição, sábado de manhã, não havia ainda ninguém por ali" (Arêas, 2018, p. 68).

No confronto com as imagens ampliadas, a visitante vislumbra, tal como a Alice de Carroll, um convite ao desconhecido. $\mathrm{O}$ embate nos mostra que, no limiar da racionalidade entre literatura e fotografia, existem formas artísticas e mundos fantásticos, com os quais nos deparamos em sonhos. E a aventura da visitante também aponta para universos misteriosos: "Parecia um sonho. Talvez a porta antiga, por onde entrara e que imitava a casa, tivesse sido o estopim da fantasia" (Arêas, 2018, p. 69).

O labirinto percorrido na exposição de Costi incita visões insólitas, multiplicações de imagens, assim como deformações e distorções de perspectiva numa singular criação catóptrica: "Estaria morta? Pois seus olhos tinham uma estranha fixidez, principalmente o esquerdo, atingido pela luz" (Arêas, 2018, p. 67).

A intervenção da especularidade torna a cena ambígua, já que a espectadora não tem certeza do que encontra ali retratado. Por isso, o espelho reflete o que não é acessível à tela e ao mesmo tempo revela certa incongruência em relação ao todo representado: "o espelho realiza uma reciprocidade de olhares que faz oscilar o interior e o exterior, une reflexos refletores e reflexos refletidos e leva a imagem a sair da sua moldura ao mesmo tempo em que convida os visitantes a entrar no quadro" (Dallenbach, 1972, p. 64, tradução nossa).

Sem dúvida, longe de ser o espaço euclidiano, a exposição é o foco de outros lugares e instâncias, cujas relações de proximidade podem ser bem diversas das vizinhanças originárias, exprimindo reflexões ou "um ponto sensível pelo qual o autor inaugura sua própria crítica" (Butor, 1974, p. 46). Passar pela mostra e detalhá-la com precisão inevitavelmente leva a personagem a medi-la a partir de todas as imagens presentes no pensamento. Com Malraux dizemos que tal operação intelectual se opõe fundamentalmente ao abandono que permite somente a contemplação, revelando-se como "um confronto de metamorfoses" (Malraux, 2006, p. 12, tradução nossa).

O olhar da personagem é, portanto, guiado pela reflexão. A fotografia interfere na literatura, pois as escritas interagem numa experiência visual e cumulativa. Por conseguinte, é na dinâmica de espelhamentos que Instantâneo da desmedida se enovela, demarcando na escrita o impulso funcional da própria narrativa.

A metáfora especular pode abranger relações não só simétricas, mas, antes de tudo, assimétricas da realidade, criando ou revertendo imagens de sujeitos, objetos e situações, as quais não se esgotam na simples apreensão da realidade, uma vez que transpõem limites. Desse modo, confirma-se a abordagem aqui utilizada, no sentido de que o termo mise en abyme é sustentado, antes de tudo, pelo alcance da metáfora especular. Cumpre ressaltar que a especularidade aí contida não revela a imagem narcísica da personagem, mas seu contrário, levando-a a uma rede complexa de identificação e reflexão. Assim, é conduzida a uma aventura desconhecida, movida por um torpor, sem deixar de testar as potencialidades da linguagem: "Foi uma sensação estranha. Ainda mais com aquela morta na capa" (Arêas, 2018, p. 68).

Com efeito, por meio das fotografias, o texto constrói-se impregnado de marcas metalinguísticas, as quais desejam dar forma ao relato da visitante e recuperar, a duras penas, $\mathrm{o}$ transe que a perturbou. É nesse ponto, pois, que consideramos cabível recuperar a importância da mise en abyme enquanto expediente teórico potencial, que emprega a reflexividade a fim de espelhar e desdobrar o enredo, considerando as instâncias de enunciação e enunciado: "ela [mise en abyme] estende o seu poder de irradiação a todo o romance, que sacraliza e destemporaliza até fazer dele uma gesta situada in illo tempore" (Dallenbach, 1979, p. 58).

Nessa arquitetura en abyme, a protagonista encerra, então, a prova-limite de sua peregrinação, evocando o poema A casa do mundo, de Luíza Neto Jorge (1939-1989):

Aquilo que às vezes parece

um sinal no rosto

é a casa do mundo 
é um armário poderoso

com tecidos sanguíneos guardados

e a sua tribo de portas sensíveis (Neto Jorge, 1973, s.p. apud Arêas, 2018, p. 71).

\section{Considerações finais}

Como numa ciranda de espelhos, a conclusão não pode senão identificar Instantâneo da desmedida como uma força ao mesmo tempo centrípeta e centrífuga do volume Um beijo por mês, justificado pela sua heterogeneidade, já que converge para o lugar textual em que todos os demais instantâneos se adensam e se coagulam, encontrando uma espécie de ápice. A escritora então, instalando-se no limiar da voz e da escuta, apresenta-se como observadora tanto das fotografias confusas que a rodeiam quanto da própria literatura que a envolve e que leva o leitor aos limites recônditos e indecifráveis das duas artes.

Nesta altura, cabe retomar alguns pontos desenvolvidos no início deste artigo. O primeiro compreende o pressuposto de que toda exposição artística se revela como um sistema discursivo e complexo. Desenvolvidas em determinados ambientes, as exposições estabelecem ligações entre os visitantes e os elementos presentes no espaço circunscrito, resultando, sem dúvida, na elaboração de sentido por parte do espectador. Tal elaboração é geralmente imprevisível, o que não impede que a mostra seja avaliada e compreendida pelos recursos que coloca em jogo. Certamente, a produção in situ constitui uma estratégia diligente na arte contemporânea, na qual a obra tem como proposta o diálogo com os elementos e os referenciais do espaço em que é integrada. Estabelecer um confronto ou ligação em relação a esses elementos nem sempre evidentes nos trabalhos é tarefa árdua do espectador. Outro aspecto a ser considerado diz respeito à produção de arte contemporânea, que, compreendida como uma forma de resistência aos mecanismos de dominação e alienação, apresenta-se como um meio fértil de reflexão crítica acerca do mundo e dos próprios sistemas artísticos. A composição do texto de Vilma Arêas relaciona-se a essa resistência, na medida em que propõe uma zona de indiferenciação entre literatura e fotografia, em curiosa construção literária.

As mudanças de escalas firmam com os instantâneos de Vilma Arêas uma estreita ligação. No mais, a visita à exposição de Rochelle Costi resulta em dedução consternadora semelhante à viagem de Alice aos imprevisíveis jogos e situações. No entanto, tais jogos ultrapassam o circuito humano, transferindo-se para o plano ficcional e reflexivo, no qual contracena a visitante e sua fruição. Logo, a estrutura de espelho é apreendida a partir da própria relação do sujeito com o real, não se esgotando na mera captação da realidade, uma vez que ultrapassa limites. O espelho é aqui entendido como um processo fulcral de escrita, aspecto medular de uma literatura que se dobra, desdobra e redobra em si mesma, revelando-se múltipla e caleidoscópica.

A capacidade reveladora de permitir o alcance de elementos não acessíveis à visão pura torna possível a discussão em torno da intrigante estrutura espelhada presente em Instantâneo da desmedida. Nesse contexto, a mise en abyme surge como procedimento narrativo associado à função especular, caracterizando-se como um instrumento de realce à imagem refletida em sua duplicidade. Seu funcionamento reitera os contornos e propriedades do objeto refletido. Ao leitor, cabe adentrar esse jogo e aceitar suas regras.

\section{Referências}

ARÊAS, Vilma (2018). Instantâneo da desmedida. In: ARÊAS, Vilma. Um beijo por mês. São Paulo: Luna Parque.

BARBOSA, Daniel (2010). Visões do contemporâneo. O tempo, Belo Horizonte, 23 set. Disponível em: http:/ / bit.ly/2PrxF99Acesso em: 22 mar. 2020.

BARTHES, Roland (1987). O prazer do texto. Tradução de J. Guinsburg. São Paulo: Perspectiva.

BUTOR, Michel (1974). Repertório. Tradução de Leyla Perrone-Moisés. São Paulo: Perspectiva. 
CHAVES, Rita (2018). A propósito de narrativas e desassossego em Vilma Arêas. In: ARÊAS, Vilma. Um beijo por mês. São Paulo: Luna Parque.

COSTI, Rochelle. (2005). "A precariedade me estimula”, afirma Rochelle Costi em entrevista. [Entrevista a] Augusto Olivani. Uol, Diversão e Arte. 9 dez. Disponível em: https:/ / bit.ly/3qlD6Dg Acesso em: 22 mar. 2020.

CYPRIANO, Fábio (2005). Rochelle Costi busca o universal no doméstico. Folha de S. Paulo, Ilustrada, São Paulo, 19 nov. Disponível em: https://www1.folha.uol.com.br/fsp/ilustrad/fq1911200514.htm Acesso em: 22 mar. 2020.

DALLENBACH, Lucien (1972). Le livre et ses miroirs dans l'oeuvre romanesque de Michel Butor. Paris: Archives des Lettres Modernes.

DALLENBACH, Lucien (1977). Le recit spéculaire: essai sur la mise en abyme. Paris: Seuil.

DALLENBACH, Lucien (1979). Intertexto e autotexto. Intertextualidades: Revista de Teoria e Análises Literárias, Coimbra, n. 27, p. 51-76. Tradução do original Poétique - Revue de Théorie et d'Analyse Littéraires por Clara Crabbé Rocha.

DUCHAMP, Marcel (1986). O ato criador. In: BATTCOCK, Gregory (Org.). A nova arte. 2. ed. São Paulo: Perspectiva.

GIDE, André (1948). Journal: tome I (1887-1925). Paris: Gallimard.

JAFFE, Noemi (2018). Um beijo por mês não dramatiza o dramático. Folha de S. Paulo, Ilustrada, São Paulo, 5 maio. Disponível em: http:/ / bit.ly/2Oli5eN Acesso em: 22 mar. 2020.

LABEILLE, Véronique (2011). Manipulation de figure: le miroir de la mise en abyme. Montréal: Centre de recherche sur le texte et l'imaginaire. p. 89-104.

MALRAUX, André (1996). La politique, la culture. Paris: Gallimard.

MALRAUX, André. (2006) Le musée imaginaire. Paris: Gallimard.

NETO JORGE, Luíza (1973). Os sítios sitiados. Lisboa: Plátano.

SONTAG, Susan (2004). Sobre fotografia: ensaios. Tradução de Rubens Figueiredo. São Paulo: Companhia das Letras. 